\title{
Multi-Vessel Coronary Artery Disease: Choice of Myocardial Revascularization Strategy
}

\author{
Nestor Seredyuk ${ }^{1^{*}}$ (D), Andrii Matlakh², Yaroslava Vandzhura ${ }^{1}$ (D), Mykyta Bielinsky ${ }^{1}$ (D), \\ Oleksii Skakun ${ }^{1}$ iD, Ruslana Denina ${ }^{1}$ (iD
}

\begin{abstract}
Multi-vessel coronary artery disease is quite a common state, which is often diagnosed by coronary angiography in patients with both stable coronary artery disease and acute coronary syndromes. Major difficulties in percutaneous coronary intervention include stent thrombosis and the need for antiplatelet therapy (aspirin and a P2Y 12 inhibitor). Stent thrombosis leads to the recurrence of myocardial infarction and may occur within the first few hours after percutaneous coronary intervention. The use of dual antiplatelet therapy, especially that combined with low-molecular-weight heparin in the first days after myocardial infarction, poses a risk of bleeding, which often occurs in real clinical practice. Among $\mathrm{P}_{2} \mathrm{Y}_{12}$ inhibitors, ticagrelor causes bleeding somewhat more frequently than clopidogrel. A case of multi-vessel coronary artery disease is described in this paper. Coronary angiography revealed right-dominant circulation; occlusion of the proximal and medial segments of the right coronary artery, thrombolysis in myocardial infarction flow grade 0; stenosis of the left main coronary artery (50-60\%), thrombolysis in myocardial infarction flow grade 2; diffuse stenosis of the medial and distal segments of the left anterior descending artery, thrombolysis in myocardial infarction flow grade 1; stenosis of the proximal segment of the left circumflex artery (> 75\%), thrombolysis in myocardial infarction flow grade 1. The patient underwent percutaneous coronary intervention; the stents were implanted in the infarct-dependent right coronary artery. The clinical course was complicated by early stent thrombosis with subsequent thrombus extraction; a day later melena developed. Bleeding was stopped, the intensity of antithrombotic therapy was reduced: the combination of aspirin and ticagrelor was replaced by the combination of aspirin and clopidogrel. Six weeks after stenting of the infarct-dependent coronary artery, complete myocardial revascularization (hybrid intervention) was performed: coronary artery bypass grafting [the left internal mammary artery $\rightarrow$ the left anterior descending artery], coronary autogenous bypass grafting [the aorta $\rightarrow$ the right coronary artery and the aorta $\rightarrow$ the left circumflex artery]. The role of fractional flow reserve or instantaneous wave-free ratio-controlled complete myocardial revascularization techniques is discussed. The following algorithm for myocardial revascularization was used: percutaneous coronary intervention for the right coronary artery + coronary artery bypass grafting-3: the left internal mammary artery $\rightarrow$ the left anterior descending artery, the aorta $\rightarrow$ the left circumflex artery, the aorta $\rightarrow$ the right coronary artery.
\end{abstract}

\section{Keywords}

Revascularization; Percutaneous Coronary Intervention; Coronary Artery Bypass Grafting; Fractional Blood Flow Reserve; Acute Myocardial Infarction

${ }^{1}$ Department of Internal Medicine No 2 and Nursing, Ivano-Frankivsk National Medical University, Ivano-Frankivsk, Ukraine

${ }^{2}$ Ivano-Frankivsk Regional Clinical Cardiology Center, Ivano-Frankivsk, Ukraine

*Corresponding author: seredyuknestor@gmail.com 


\section{Background}

Multi-vessel coronary artery disease (MVCAD) is observed in 30-60\% of cases of acute ST-segment elevation myocardial infarction (STEMI) [1]. Coronary artery bypass grafting (CABG) in patients with MVCAD makes it possible to achieve complete revascularization, which prevents angina attacks, improves the quality of life, increases exercise tolerance $[1,2]$.

However, advanced age, left ventricular dysfunction, acute heart failure (AHF), cardiogenic shock, and comorbidity worsen the prognosis in patients undergoing CABG [2-4]. Both miniinvasive $\mathrm{CABG}$ revascularization technique $[3,4]$ and hybrid reperfusion using percutaneous coronary intervention (PCI) with stent implantation in the infarct-dependent coronary artery (IDCA) and coronary artery bypass grafting of remaining arteries with stenoses of more than 50\% [2] were important steps in cardiac surgery. The variant of complete myocardial revascularization along with stent implantation in all the coronary arteries with hemodynamically significant stenoses is widely discussed [5-7]. The efficiency of this strategy increases with the use of FFR-controlled revascularization $[9,12]$. This technique requires the study of the so-called fractional flow reserve (FFR), that is the ratio of a coronary artery pressure proximal and distal to stenosis (normal value is $>0.80$ ). This technique requires the measurement of coronary pressure under conditions of maximum vasodilation, which is achieved by intravenous adenosine. A modified version of this ratio is the criterion of the instantaneous wave-free ratio (iFR) that is a transcoronary gradient during the diastolic wave-free period. The iFR technology determines the level of pressure distal to the stenosis (Pd) and in the aorta (Pa) - Fig. 1. The method of determining the iFR does not require the use of vasodilators; it is simple, safe, and cheap. For the iFR, the criterion for deciding about expediency of stent implantation in all the coronary arteries with intermediate grade stenosis $(40-90 \%)$ is the value of 0.89 (Fig. 2). If the value of the FFR is $>0.80$, or the iFR is $>0.89$, stent implantation in the coronary artery with such stenosis is not appropriate and can be delayed, and if the value of the FFR is $<0.80$, or the $\mathrm{iFR}$ is $<0.89, \mathrm{PCI}$ is appropriate.

Therefore, iFR-controlled stent implantation is recommended for stenoses with narrowing of the lumen at the range of $40-90 \%$ and the values of the iFR $<0.89$, or FFR $<0.80$. The Fractional Flow Reserve Versus Angiography for Multivessel Evaluation 2 (FAME2) study confirmed better efficacy of FFR (iFR) -guided PCI as compared to only optimal medical treatment (OMT) (hazard ratio (HR) 0.32 [95\% confidence interval (CI) 0.19-0.53; $\mathrm{p}<0.001$ ]) [9-11]. In Ukraine, FFR/iFR-guided PCI is performed in the Institute of Cardiology named after Academician M.D. Strazhesko of the National Academy of Medical Sciences Of Ukraine, Heart Institute of the Ministry of Health of Ukraine, National Institute of Cardiovascular Surgery named after M.M. Amosov of the National Academy of Medical Sciences of Ukraine. There is a reason to believe such a method will soon be used in all the reperfusion centers of Ukraine.

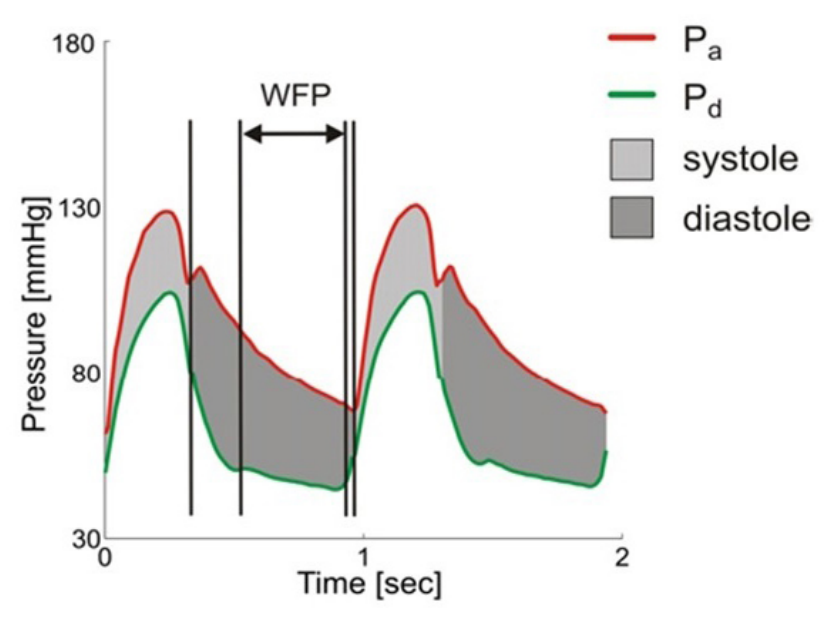

Figure 1. IFR measurement. Adopted from Berry C et al. [13]

\section{Clinical iFR and FFR Cut-points}

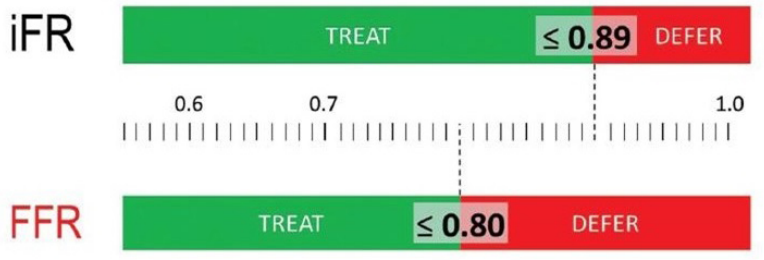

Figure 2. Reference range of the iFR and FFR. Adopted from Davies JE et al. [14].

The paper presents an example of two-stage myocardial revascularization in STEMI with MVCAD and complication after the first stage - PCI (without the use of FFR/iFR-guided stent implantation).

\section{Case Report}

A 76-year-old man P. was admitted with complaints of very intense squeezing pain behind and to the left of the sternum with irradiation to the lower jaw and the left scapular area, which had appeared suddenly, lasted more than an hour, was accompanied by shortness of breath, palpitations, cold sweating, fatigue. Pulse rate was $118 \mathrm{bpm}$ with weak filling; blood pressure was 110/80 $\mathrm{mm} \mathrm{Hg}$ (his usual blood pressure was at the range of 160-170/90-100 $\mathrm{mm} \mathrm{Hg}$ ); heart sounds were weakened, there was protodiastolic gallop rhythm. There were auscultated moist rales ( $>50 \%$ of the lung area; AHF (Killip class III/ Forrester class IV)). An electrocardiogram (ECG) revealed sinus rhythm, left axis deviation; QS-pattern with ST-segment elevation (J-I $0.08 \mathrm{~s}=2.5-3.0 \mathrm{~mm}$ ) in leads II, III, aVF, $\mathrm{V}_{1}-\mathrm{V}_{4}$; qrS-pattern with an elevation of segment ST $\left(\mathrm{J}-\mathrm{I} 0.08 \mathrm{~s}=2 \mathrm{~mm}\right.$ ) in leads $\mathrm{V}_{5}-\mathrm{V}_{6}$. Some previous ECGs 
revealed atrial fibrillation.

ECG report: ischemic myocardial injury with transmural necrosis in areas supplied by the right coronary artery (RCA) and the left main coronary artery (LMA).

Laboratory tests revealed high cardiac troponin I $(125 \mathrm{ng} / \mathrm{ml})$, leukocytosis $\left(27.4 \times 10^{6} / \mathrm{ml}\right)$, hyperuricemia (670 $\mu \mathrm{mol} / \mathrm{l})$, high creatinine level $(110.0 \mu \mathrm{mol} / \mathrm{l})$.

Coronary angiography revealed right-dominant circulation; occlusion of the proximal and mid RCA, thrombolysis in myocardial infarction (TIMI) flow grade 0; stenosis of the LMA (50-60\%), TIMI-2; diffuse stenosis of the medial and distal segments of the left anterior descending artery (LAD) (75-90\%), TIMI-1; stenosis of the proximal left circumflex artery (LCx) (> 75\%), TIMI-1.

Heart Team decision: a 76-year-old patient P. needs surgical revascularization $(\mathrm{CABG})$, but due to the impossibility of performing CABG urgently and AHF (Killip class III/ Forrester class IV) development, hybrid intervention, namely primary PCI and elective CABG (in 6 weeks) is recommended. Periprocedural support included aspirin - $300 \mathrm{mg}$, ticagrelor $180 \mathrm{mg}$, unfractionated heparin - $5000 \mathrm{IU}$.

PCI protocol: two Terumo bare-metal stents (BMS) $(3.0 \times 23.0 \mathrm{~mm}$ and $3.0 \times 15.0 \mathrm{~mm})$ were implanted in the proximal and mid RCA (stent-by-stent technique); control angiography showed complete restoration of the blood flow in the RCA (Fig. 3).
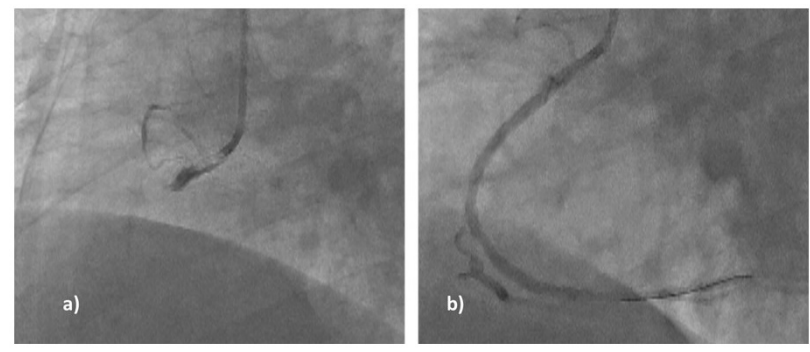

Figure 3. Primary PCI performed in patient P.: a) proximal RCA occlusion, TIMI-0; b) blood flow restoration, TIMI-3.

One hour after the procedure, the patient's condition suddenly deteriorated: chest pain and cold sweating resumed; elevation of the ST segment in leads II, III, aVF (4 mm) increased (Fig. 4). Control coronary angiography revealed thrombosis of the implanted stents and dissection of the mid RCA.

The extraction of thrombotic masses from the lumen of the stents in the proximal and mid RCA and optimization of the implanted stents were performed; the blood flow was restored with the result of TIMI-3. Dual antiplatelet therapy (DAPT) including aspirin $100 \mathrm{mg} / \mathrm{d}$ and ticagrelor $180 \mathrm{mg} / \mathrm{d}$; anticoagulants - enoxaparin at a dose of $1 \mathrm{mg} / \mathrm{kg}$ twice a day; nitrates - isosorbide mononitrate $20 \mathrm{mg}$ twice a day were prescribed to the patient.

Within the day after PCI, the patient's condition was satis- factory; however, next morning, after defecation, melena was noted, that resulted in discontinuing DAPT and performing esophagogastroduodenoscopy. In the cardiac region of the stomach, bleeding ulcer was found (there was no reference to gastric ulcer in the patient's medical history); Mallory-Weiss syndrome was diagnosed. Active hemostatic therapy was started, which proved to be effective. De-escalation of DAPT was performed: clopidogrel at a dose of $75 \mathrm{mg} / \mathrm{d}$ was prescribed instead of ticagrelor at a dose of $180 \mathrm{mg} / \mathrm{d}$. Drug therapy was supplemented with rosuvastatin $(20 \mathrm{mg} / \mathrm{d})$, bisoprolol ( $2.5 \mathrm{mg} / \mathrm{d})$, ramipril $(2.5 \mathrm{mg} \rightarrow 5.0 \mathrm{mg} / \mathrm{d})$, corvitin $(500 \mathrm{mg}$ in $50 \mathrm{ml}$ of $0.9 \% \mathrm{NaCl}$ solution intravenously) and pantoprazole $(40 \mathrm{mg} / \mathrm{d})$.

Subsequently, the rehabilitation period (the first and the second stages) was uneventful.

\section{Laboratory findings.}

Complete blood count:

- hemoglobin $(\mathrm{Hb})-128 \mathrm{~g} / \mathrm{l}$;

- erythrocytes $4.04 \mathrm{~T} / 1$;

- color index 0.95 ;

- platelets $274 \times 10^{9} / 1$;

- erythrocyte sedimentation rate (ESR) $16 \mathrm{~mm} / \mathrm{h}$;

- leukocytes $9.7 \times 10^{9} / 1$, including bands $-8 \%$, segmented neutrophils $-72 \%$, lymphocytes $-25 \%$, monocytes $3 \%$, eosinophils $-2 \%$.

Biochemical analysis of blood:

- total protein - $74.4 \mathrm{~g} / \mathrm{l}$;

- creatinine - $122.2 \mu \mathrm{mol} / \mathrm{l}$

- aspartate aminotransferase (AST) - 58.8 IU;

- alanine aminotransferase (ALT) - 91.7 IU;

- total bilirubin - $15.1 \mu \mathrm{mol} / \mathrm{l}$;

- potassium - $4.99 \mathrm{mmol} / \mathrm{l}$;

- sodium - $137.3 \mathrm{mmol} / \mathrm{l}$;

- calcium - $1.8 \mathrm{mmol} / \mathrm{l}$

- chlorine - $103.3 \mathrm{mmol} / \mathrm{l}$.

Lipid profile:

- total cholesterol - $3.8 \mathrm{mmol} / \mathrm{l}$

- triacylglycerols - $1.33 \mathrm{mmol} / \mathrm{l}$;

- high-density lipoprotein (HDL) - $1.8 \mathrm{mmol} / \mathrm{l}$;

- low-density lipoprotein (LDL) - $1.39 \mathrm{mmol} / \mathrm{l}$;

- very-low-density lipoprotein (VLDL) - $0.6 \mathrm{mmol} / \mathrm{l}$.

Coagulogram:

- the prothrombin index (PTI) $-83.0 \%$;

- the activated partial thromboplastin time (APTT) - 90.3s;

- the international normalization ratio (INR) - 1.23;

- fibrinogen - $2.64 \mathrm{~g} / \mathrm{l}$;

- hematocrit $(\mathrm{Ht})-0.44$.

Urine analysis: there were observed normal values.

\section{Echocardiography:}

aorta $-2.4 \mathrm{~cm}$, aortic valve leaflets were thickened, the maximal pressure gradient was $13.2 \mathrm{~mm} \mathrm{Hg}$; the left atrium $3.9 \mathrm{~cm}$; mitral valve - M-type opening, fibrosis of the leaflets; the ratio between $\mathrm{E}$-wave and $\mathrm{A}$-wave (E/A ratio) - 0.97; end-diastolic left ventricular diameter (EDLVD) $-5.6 \mathrm{~cm}$, 

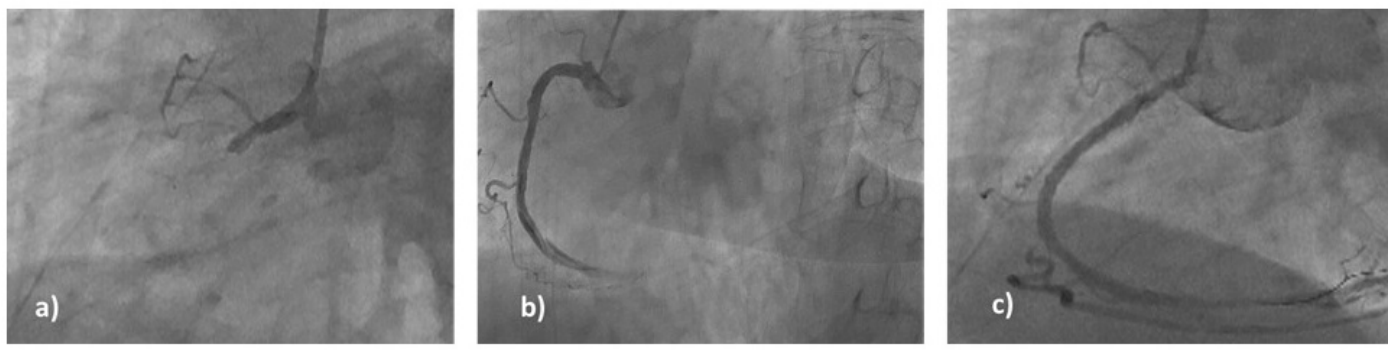

Figure 4. Repeated coronary angiography in patient P.: a) proximal RCA reocclusion, TIMI-0; b) dissection of the mid RCA; c) RCA after stent optimization, TIMI-3.

end-systolic left ventricular diameter (ESLVD) $-4.3 \mathrm{~cm}$, enddiastolic left ventricular volume (EDLVV) - $154 \mathrm{ml}$, endsystolic left ventricular volume (ESLVV) - $82.0 \mathrm{ml}$, left ventricular ejection fraction (LVEF) - 47\%; hypokinesia of the inferior wall of the LV and ventricular septum (VS), the thickness of the VS $-1.3 \mathrm{~cm}$ in diastole, $1.4 \mathrm{~cm}$ in systole (systolic thickening $-0.1 \mathrm{~cm}$ ), the thickness of the left ventricular free wall (LVFW) in diastole $-0.90 \mathrm{~cm}$, in systole $-0.95 \mathrm{~cm}$ (systolic thickening $-0.05 \mathrm{~cm}$ ), the relative wall thickness of the LV $-0.39 \mathrm{~cm}$ (eccentric LV hypertrophy); right ventricular diameter (RVD) $-3.2 \mathrm{~cm}$, the systolic pressure in the pulmonary artery $-37 \mathrm{~mm} \mathrm{Hg}$; separation of pericardial layers 4-5 $\mathrm{mm}$.

\section{Conclusions:}

Fibrosis of the atrioventricular (AV) and mitral valves (MV); LV diastolic dysfunction, type I; eccentric LV hypertrophy; hypokinesia of the inferior wall and anterior-septal and apical segments of the LV, the wall motion score index $($ WMSI $)=$ $1.75, \mathrm{LVEF}_{\mathrm{WMSI}^{-}}-47.5 \%$ (mid-range).

The risk of the fatal cardiovascular event within the following 10 years based on the Systematic Coronary Risk Evaluation (SCORE) and atherosclerotic cardiovascular disease (ASCVD) risk scales was found to be $27 \%$ and $19.9 \%$, respectively. The risk of thrombosis on the $\mathrm{CHA}_{2} \mathrm{DS}_{2}$-VASc scale was 5 points (high), the risk of hemorrhagic complications on the PRECISE-DAPT scale $>25$ points (high). The duration of DAPT was limited up to 1 month due to the high risk of hemorrhagic complications.

After 6 weeks, the patient was admitted to the second stage of revascularization and underwent CABG: the left internal mammary artery (LIMA) $\rightarrow$ the LAD, the aorta $\rightarrow$ the LCx, the aorta $\rightarrow$ the RCA.

The postoperative period was uneventful.

\section{Clinical diagnosis:}

Coronary artery disease: acute transmural STEMI of the inferior, anterior-septal, and apical segments of the LV (circular), AHF (Killip class III/Forrester class IV) (14.03.2017). Urgent coronary angiography (14.03.2017): occlusion (100\%) of the proximal RCA, TIMI-0; stenosis (50-60\%) of the LMA, TIMI-2; diffuse stenosis of the LAD, TIMI-1; stenosis of the proximal LCx, TIMI-1.

Ad hoc stenting (14.03.2017) of the proximal and medial RCA with BMS stents (3.0x23.0 mm and 3.0x15.0 mm), TIMI-3; early stent thrombosis, TIMI-0, dissection of the medial segment of the RCA; thrombextraction, optimization of the implanted stents, TIMI-3.

\section{Complications:}

Bleeding ulcer of the cardiac region of stomach, MalloryWeiss syndrome were treated pharmacologically (15.03.2017). CABG3: the LIMA $\rightarrow$ the LAD, the aorta $\rightarrow$ the RCA, the aorta $\rightarrow$ the LCx (26.04.2017).

Cardiosclerosis (diffuse and postinfarction). Atrial fibrillation, paroxysmal form, the European Heart Rhythm Association (EHRA) score - IIb, the $\mathrm{CHA}_{2} \mathrm{DS}_{2}$-VASc score -5 points, the PRECISE-DAPT score $>25$ points. Stage IIA chronic heart failure according to the classification of V.H. VasylenkoM.D. Strazhesko, stage $\mathrm{C}$ according to the American College of Cardiology/American Heart Association (ACC/AHA) Guidelines, H3L2M2, mid-range LVEF, functional class (FC) III according to the New York Heart Association (NYHA).

Concomitant diseases: stage III, grade 2, risk 4 (very high) arterial hypertension; asymptomatic hyperuricemia.

In this clinical case, on the background of atherosclerotic lesions of all the coronary arteries, acute transmural STEMI of the inferior and anteroseptal and lateral segments of the LV (circular) developed; it was complicated by AHF (Killip class III/ Forrester class IV), early thrombosis of the implanted stents, dissection in the mid RCA (corrected by the extraction of the thrombus from the implanted stents and re-optimization of the stents), gastric bleeding.

Due to the complicated course of STEMI, Heart Team decided to postpone surgical revascularization for 6 weeks after urgent PCI (stent implantation in the RCA).

Hybrid revascularization using PCI with stent implantation in the infarct-dependent RCA and delayed complete surgical revascularization were performed according to the 
European Society of Cardiology/the European Association for Cardio-Thoracic Surgery (ESC/EACTS) guidelines [5].

An ongoing research and experience exchange regarding complete revascularization by FFR- or iFR-guided PCI are being conducted now [6-12].

The best options for hybrid interventions are CABG LIMA $\rightarrow$ LAD + non-LAD PCI with simultaneous or sequential PCI with stent implantation in the arteries with intermediate stenoses, CABG LIMA $\rightarrow$ LAD, and then PCI non-LAD arteries that supply blood to other areas of the ischemic myocardium and the variant of MIDCABG $\rightarrow$ LIMA + PCI non-LAD. It is also possible to use the scheme CABG2 + PCI LAD, or MIDCABG 2 + PCI LAD [2, 3].

In the presented case, the algorithm for complete revascularization was as follows: PCI RCA + CABG3: LIMA $\rightarrow$ LAD, Ao $\rightarrow$ LCx, Ao $\rightarrow$ RCA (Fig. 5).

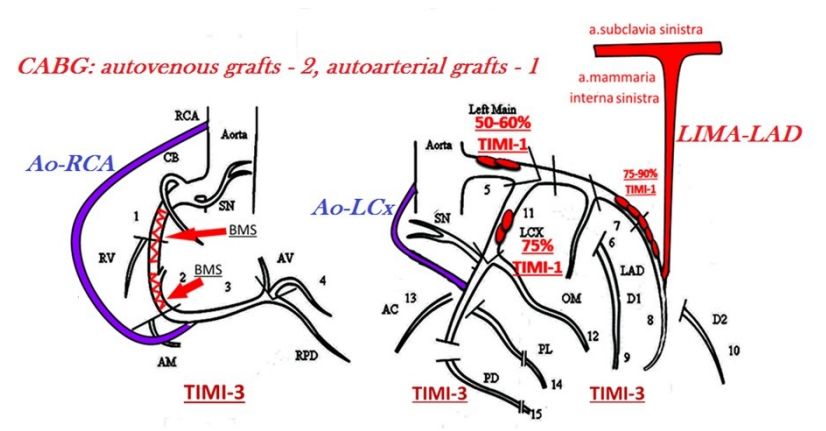

Figure 5. Scheme of myocardial revascularization performed.

$\mathrm{CABG} 3: \mathrm{LIMA} \rightarrow \mathrm{LAD}, \mathrm{Ao} \rightarrow \mathrm{LCx}, \mathrm{Ao} \rightarrow \mathrm{RCA}$ Ao - aorta.

\section{Conclusions}

1. In the coexistence of MVCAD and STEMI and in the absence of the possibility of FFR- or iFR-guided PCI with complete myocardial revascularization, the strategy of choice should be primary PCI with stent implantation in the infarction-dependent artery and subsequent CABG with complete myocardial revascularization (hybrid revascularization).

2. Early complications of PCI (stent thrombosis, coronary artery dissection, gastrointestinal bleeding) are reasons for delaying the next stage of $\mathrm{CABG}$; however, they are not an obstacle for performing complete reperfusion.

3. Complete revascularization in complicated PCI should be performed not later than 8 weeks after the opening of the infarction-dependent coronary artery using PCI.

4. Complete myocardial revascularization with PCI RCA + CABG3: LIMA $\rightarrow$ LAD, Ao $\rightarrow$ LCx, Ao $\rightarrow$ RCA may be the strategy of choice for patients with a diagnosis of STEMI urgently admitted to a reperfusion center without the possibility of emergency surgical revascularization within the first 12-24 hours.

\section{Ethical Statement}

The research was conducted according to the Declaration of Helsinki.

\section{Informed Consent}

Informed consent was obtained from the patient participating in this study.

\section{Conflict of Interest}

The authors declare that no conflicts exist.

\section{Financial Disclosure}

This research received no specific grant from any funding agency, commercial or not-for-profit sectors.

\section{References}

[1] Obeid MA, Abdurakhmanov AA, Mashrapov OA, Ganiyev US. The results of surgical revascularization in patients with multi-vessel coronary disease. Inter Collegas [Internet]. 2017 Feb 5;3(4):163-5. Available from: https://doi.org/10.35339/ic.3.4.163-165

[2] Gabrielyan A, Domanskyy T, Beregovoy O. Method of hybrid revascularization of miocard in patients with atherosclerotic damage of coronary vessels. Ukr J Cardiovasc Surg [Internet]. 2018 May 14;25(3):18-21. Available from: https://doi.org/10.30702/ujcvs/18.31/03(018-021)

[3] Demianenko VM, Babliak OD, Babliak DY, Stohov OS, Melnyk EA, Revenko KA, et al. Features of Cardiopulmonary Bypass in Mininvasive Multivessel Coronary Artery Bypass Grafting. Ukr J Cardiovasc Surg [Internet]. 2019 May 22;137(14):18-22. Available from: https://doi.org/10.30702/ujcvs/19.3505/0370018-022

[4] Kozlov KL, Mihajlov SS, Shishkevich AN, Oleksyuk IB, Sedova EV, Rybin EV, et al. Opyt etapnoy gibridnoy revaskulyarizatsiyi patsiyenta pozhilogo vozrasta $\mathrm{s}$ generalizovannym aterosklerozom. Klinicheskaya Gerontologiya. $2013 ;(5): 46-8$.

[5] Shilov AA, Kochergin NA, Ganyukov VI, Kozyrin KA, Barbarash OL. Immediate results of three methods of surgical myocardial revascularization in multivessel lesion of the coronary bed. Angiol Vasc Surg [Internet]. 2019 May 22;25(3):135. Available from: https://doi.org/10.33529/ANGI02019314

[6] Neumann F-J, Sousa-Uva M, Ahlsson A, Alfonso F, Banning AP, Benedetto U, et al. 2018 ESC/EACTS Guidelines on myocardial revascularization. Eur Heart J [Internet]. 2019 Jan 7;40(2):87-165. Available from: https://doi.org/10.1093/eurheartj/ehy394 
[7] Engstrøm T, Kelbæk H, Helqvist S, Høfsten DE, Kløvgaard L, Holmvang L, et al. Complete revascularisation versus treatment of the culprit lesion only in patients with ST-segment elevation myocardial infarction and multivessel disease (DANAMI-3-PRIMULTI): an open-label, randomised controlled trial. Lancet [Internet]. 2015 Aug 7;386(9994):665-71. Available from: https://doi.org/10.1016/S0140-6736(15)60648-1

[8] Fearon WF, Nishi T, De Bruyne B, Boothroyd DB, Barbato E, Tonino P, et al. Clinical Outcomes and Cost-Effectiveness of Fractional Flow Reserve-Guided Percutaneous Coronary Intervention in Patients With Stable Coronary Artery Disease. Circulation [Internet]. 2018 Jan 30;137(5):480-7. Available from: https://doi.org/10.1161/CIRCULATIONAHA.117.031907

[9] Nishi T, Piroth Z, De Bruyne B, Jagic N, MöbiusWinkler S, Kobayashi Y, et al. Fractional Flow Reserve and Quality-of-Life Improvement After Percutaneous Coronary Intervention in Patients With Stable Coronary Artery Disease. Circulation [Internet]. 2018 Oct 23;138(17):1797-804. Available from: https://doi.org/10.1161/CIRCULATIONAHA.118.035263

[10] Xaplanteris P, Fournier S, Pijls NHJ, Fearon WF, Barbato E, Tonino PAL, et al. Five-Year Outcomes with PCI Guided by Fractional Flow Reserve. N Engl J Med [Internet]. 2018 Jul 19;379(3):250-9. Available from: https://doi.org/10.1056/NEJMoa1803538
[11] Ciccarelli G, Barbato E, Toth GG, Gahl B, Xaplanteris P, Fournier S, et al. Angiography Versus Hemodynamics to Predict the Natural History of Coronary Stenoses. Circulation [Internet]. 2018 Apr 3;137(14):1475-85. Available from: https://doi.org/10.1161/CIRCULATIONAHA.117.028782

[12] Khokhlov AV, Shymanko MV, C MV. Fractional flow reserve: current status. Card Surg Interv Cardiol [Internet]. 2019 May 22;137(3):5-13. Available from: https://doi.org/10.31928/2305-3127-2019.3.513

[13] Berry C, van 't Veer M, Witt N, Kala P, Bocek O, Pyxaras SA, et al. VERIFY (VERification of Instantaneous Wave-Free Ratio and Fractional Flow Reserve for the Assessment of Coronary Artery Stenosis Severity in EverydaY Practice). J Am Coll Cardiol [Internet]. 2013 Apr 14;61(13):1421-7. Available from: https://doi.org/10.1016/j.jacc.2012.09.065

[14] Davies JE, Sen S, Dehbi H-M, Al-Lamee R, Petraco R, Nijjer SS, et al. Use of the Instantaneous Wave-free Ratio or Fractional Flow Reserve in PCI. N Engl J Med [Internet]. 2017 May 11;376(19):1824-34. Available from: https://doi.org/10.1056/NEJMoa1700445

Received: 2020-09-04

Revised: 2020-09-27

Accepted: 2020-09-29 